\title{
0 distanciamento entre filosofia e política, e o sentido da política em Hannah Arendt
}

\author{
The distance between philosophy and politics, \\ and the meaning of politics in Hannah Arendt's thought
}

DOI: $10.20873 / \mathrm{rpv} 6 \mathrm{n} 2-17$

\section{Tamíris Moreira Simão}

Orcid: 0000-0002-6427-5025

Email: tamiris.msimao@gmail.com

\begin{abstract}
Resumo
Hannah Arendt identifica no pensamento de Platão aquilo que ela designa como "Tirania da Verdade", ao mesmo tempo em que nos mostra de que modo essa "tirania" se fundamenta a partir de uma cisão entre filosofia e política. Essa cisão causa uma progressiva degradação da política que deixa de ser o espaço do próprio exercício da liberdade para ser meramente aquilo que garante a existência de liberdades individuais e que preserva a reprodução da vida. Ademais, ao ser apartada da liberdade e da própria atividade do pensamento e do diálogo, a política se apropria do uso da força e a esfera política passa a ser a esfera da coerção. A política degradada, portanto, é aquela que perdeu o seu sentido, ou seja, que não proporciona espaço público para a discussão e compartilhamento de um mundo em comum. A degradação atinge seu ápice quando a pergunta "Qual é o sentido da política?" é suplantada por “Tem a política algum sentido?". Em nosso artigo, buscamos mostrar o percurso argumentativo da filósofa que se inicia com o exame da "tirania da verdade" e da cisão entre filosofia e política até a consequente perda do próprio sentido da política. Para isso, examinaremos especialmente seus textos "Filosofia e Política", "O que é autoridade?", "Tradição e Idade Moderna" e "O sentido da Política".
\end{abstract}

\section{Palavras-chave}

Política, Liberdade, Tirania da Verdade.

\begin{abstract}
Hannah Arendt identifies in Plato's thought what she calls the "Tyranny of Truth" while showing us how this "tyranny" is based on a split between philosophy and politics. This split causes a progressive degradation of politics that ceases to be the space for the exercise of freedom itself to be what guarantees the existence of individual freedoms and preserves the reproduction of life. Furthermore, by being separated from freedom, thought and dialogue, the political sphere becomes coercive. Degraded politics, therefore, has lost its meaning; that is, it does not provide a public space for discussion and sharing of a world in common. The maximum
\end{abstract}


of degradation happens when the question "What is the meaning of politics?" is superseded by "Does politics have any meaning?" In our article, we show Arendt's argumentative path, which begins with the examination of the "tyranny of truth" and the split between philosophy and politics to the consequent loss of the very meaning of politics.

\section{Keywords}

Politics, Freedom, Tyranny of Truth.

\section{Introdução}

Neste artigo, abordaremos a cisão entre filosofia e política, e a consequente degradação da política, de acordo com a obra de Hannah Arendt. Para a realização de nosso objetivo, dividiremos o nosso texto em duas partes.

Na primeira seção, abordaremos a noção de doxa platônica como opinião, que se distingue radicalmente da verdade; a vida filosófica como bios theorétikos e a divisão entre alma e corpo, como reflexo da cisão entre filosofia e política. Estudaremos, ainda, a concepção arendtiana acerca da proposta platônica do 'rei filósofo' como uma tirania da verdade, que resulta não apenas na cisão entre filosofia e política, mas também na degradação da política.

Na segunda parte, veremos como doxa possui um sentido distinto para Sócrates e, para a própria pólis, uma vez que a palavra também possui o significado de aparecer, que se relaciona diretamente à noção de espaço público grega. Apresentaremos, ainda, a primazia da esfera pública em relação à esfera privada na antiguidade e de que modo a filosofia platônica, a partir da proposta do rei filósofo, defende uma sociedade em que a maioria seja dominada, e na qual poucos usufruam da liberdade política, degradando, assim, a própria noção de política grega. Por fim, veremos como a perda da liberdade política resultou em perda do próprio sentido da política: à medida que o espaço público foi suplantado e deixou de ser o lugar da "discussão entre iguais", como era na polis ateniense, para se tornar um espaço de dominação, a política perdeu seu sentido, de tal modo que a questão "qual é o sentido da política?" foi substituída por "tem a política ainda algum sentido?" Com isso, passamos pelo ápice da degeneração da política, que ao deixar de ser o espaço livre da conversa, tornou-se o lugar do uso da força. 
Para nosso estudo, remeter-nos-emos principalmente aos textos "Filosofia e Política", presente em "A dignidade da política"; "O que é autoridade?" e "Tradição e idade moderna", ambos em "Entre o Passado e Futuro"; e "O sentido da política”, fragmento publicado no livro "O que é política?".

\section{A cisão entre Filosofia e Política}

O julgamento e a condenação de Sócrates representaram, para Arendt, um importante marco da cisão entre filosofia e política. Isso porque, de acordo com a autora, é a partir da morte de seu mestre que Platão elabora pontos centrais no afastamento e na subordinação da política em relação à Filosofia. Ou seja, assistir ao processo de julgamento socrático e testemunhar um sábio sendo obliterado pelas opiniões irresponsáveis dos atenienses foi, segundo Arendt, o que culminou na ruptura entre essas duas esferas. Para compreendermos o "abismo" sinalizado por Arendt, devemos considerar três elementos fundamentais: a renúncia à prática filosófica socrática; a alteração na concepção da doxa; e o estabelecimento da chamada "tirania da verdade platônica". Como resultado direto desses três elementos, temos a consolidação de uma tradição que foi difundida, ao longo do tempo, nas mais diversas vertentes e formas do pensamento filosófico político.

O primeiro ponto que devemos notar é o fato de que dentre os sábios gregos, Arendt considera Sócrates e sua maiêutica um acontecimento singular. No texto "Hannah Arendt: Filosofia e Política", Eduardo Jardim de Moraes analisa o modo como a autora compreende a maiêutica socrática:

A investigação socrática se caracteriza não pelo fato de buscar algum resultado, mas por pretender colocar em questão, no diálogo, as opiniões dos seus interlocutores. E o resultado desse questionamento não era a aquisição de qualquer novo conhecimento. 0 pensamento, tal como entendia Sócrates, era crítico porque envolvia a arte do krínein, (do ordenar, separar, distinguir), a arte da descriminação, mencionada por Platão no Sofista. E uma das imagens preferidas por Hannah Arendt para referir-se a Sócrates é a de uma parteira. Uma parteira que nunca ajudou a dar à luz crianças vivas, mas a desembaraçar de quimeras, de falsas opiniões. Portanto, o que está em jogo na atividade do pensamento tal como foi experimentado por Sócrates e, pensa Hannah Arendt, também por Kant, tem mais a ver com uma experiência de purificação. 0 pensamento não envolve a aquisição de algo que possa ser identificado como a verdade em filosofia. (MORAES, 2003 p. 44) 
A autora alemã aponta para o entendimento de que o fato de Sócrates justamente não se considerar um sábio poderia ser o motivo de tamanha singularidade. Sócrates se distinguia, assim, dos outros sophoi, conhecidos por não saberem o que era bom para si próprios. A respeito disso, podemos nos lembrar da famosa anedota sobre Tales que, durante um passeio, observava o céu com tamanha atenção e concentração que não conseguiu notar e desviar de um buraco na estrada. Essa caricatura, de acordo com Arendt, é um elemento importante para entendermos o modo como os sábios usualmente eram vistos, além de evidenciar a imagem construída na pólis a respeito deles, de seus interesses, de suas atividades e, principalmente, sua utilidade.

Arendt esclarece no ensaio Filosofia e Política que as questões da filosofia são marcadas por problemas e perguntas irrespondíveis. Perguntas últimas que procuram indagar sobre "qual é a origem de tudo?"; "qual a natureza do homem?"; "qual o sentido da vida?" etc. Embora respostas conclusivas e, principalmente, consensuais sobre tais questões sejam no mínimo improváveis, a capacidade de elaborar e se dedicar a tais indagações representam uma característica crucial da filosofia, de acordo com Arendt. É, aliás, a partir da proposta desse tipo de problema que outras questões, estas respondíveis, podem ganhar contorno. Nesse sentido, a escritora contemporânea diz que a filosofia é condição de possibilidade para formulação das questões que serão ocupação da ciência. Se o homem perdesse a capacidade de produzir dúvidas irrespondíveis, ele igualmente perderia a capacidade de propor perguntas respondíveis:

Esta é a razão pela qual a ciência, que faz perguntas respondíveis, deve sua origem à filosofia, uma origem que continua sendo sua fonte, sempre presente, gerações afora. Se o homem algum dia viesse a perder a faculdade de fazer as questões últimas, perderia também, do mesmo modo, sua faculdade de fazer perguntas respondíveis. Não seria mais um ser que faz perguntas, o que significaria o fim não apenas da filosofia, mas também da ciência. (ARENDT, 2002a, p. 112)

A pólis, porém, não percebeu tal importância e, consequentemente, questionou a utilidade das indagações propostas pelos sábios antigos. Além disso, esses sábios poderiam se encontrar em sérias dificuldades ao interagirem com o conjunto de cidadãos. Isso porque a sabedoria filosófica possui como marca, para Platão, o thaumadzein (espanto) e a dissolução da 
doxa ${ }^{1}$ (opinião) do indivíduo, à medida que ele avança no caminho filosófico. Desse modo, o filósofo, dentro dessa tradição, parte de uma dupla desvantagem: por um lado, o thaumadzein inicial o conduz sistematicamente ao silêncio do espanto; por outro lado, a doxa, ligada então à ideia de persuasão e ao belo discurso, é colocada em xeque por Platão. Como resultado disso, o filósofo normalmente não é capaz de ser tão eloquente quanto o cidadão que se dedicou a ornamentar e a sofisticar a sua doxa. Mais especificamente, é como se a cada novo espanto, o filósofo se conduzisse ao silêncio e perdesse sua opinião; a partir disso, ele reinicia o exame de sua questão.

A condição do filósofo a partir de seu trajeto de 'vir-a-ser' é apresentada na alegoria da caverna platônica. Nas palavras da autora: "Platão pretende dar uma espécie de biografia condensada do filósofo" que se desdobra em três estágios, "designando cada um deles um momento decisivo, uma reviravolta e formando, os três juntos, a periagôge holés téspsychés, aquela reviravolta do ser humano como um todo, que, para Platão, é justamente a própria formação do filósofo" (ARENDT, 2002a, p. 108). Tendo em vista que a referida alegoria é amplamente conhecida, e seu papel na teoria arendtiana tem sido exaustivamente trabalhada por diversos autores, consideramos pertinente omitir toda a sua descrição, atendo-nos apenas ao terceiro estágio do filósofo: seu retorno. Ao retornar à caverna, os olhos do "homem-filósofo" já não conseguem ver com tanta nitidez as sombras e, consequentemente, esse homem se encontra em desvantagem em relação aos demais, ou seja, trata-se daquela dificuldade já mencionada que o filósofo enfrenta dentro da pólis ao se relacionar com outros cidadãos.

Ademais, não bastando a desvantagem desse homem singularizado pela experiência filosófica, ele ainda se encontra em constante confronto com as opiniões correntes na pólis. Arendt entende que, para Platão, a formulação e a sofisticação das doxai é também um meio pelo qual a maioria dos homens evitam a experiência radical do thaumadzein. Contudo, ao optar pela fuga ou abstenção em relação a essa experiência, os cidadãos correntemente elaboram opiniões inadequadas sobre todos os temas. Consequentemente, ao entrar em contato com essas doxai, o filósofo primeiro discorda e, posteriormente, mostra a falsidade desses pontos de vista.

\footnotetext{
${ }^{1}$ Até aqui, estamos utilizando a compreensão de doxa, que Arendt considera como a platônica. Na segunda parte do texto, veremos como a noção de doxa é distinta para Sócrates.
} 
Afinal, com a filosofia platônica, a distinção entre diferentes pontos de vista não é mais qualitativa, ou seja, não existe uma opinião que possa ser "mais verdadeira" do que outra. A verdade é única, necessária, e só alcançada a partir da execução de um projeto de vida específico - a bios theôrétikos. 0 que não é verdade, é falso, simples simulacro; desse modo, fecha-se o campo aberto ao verossímil, à persuasão.

Essa verdade que se pretende independente e soberana, pode ser alcançada somente em breves momentos, em estalos momentâneos. Ora, é Platão quem pretende transformar esse acesso em algo permanente, e nessa tentativa "o filósofo se estabelece, baseia sua inteira existência naquela singularidade que experimentou quando foi acometido pelo pathos de thaumadzein" (ARENDT, 2002a, p. 113-114). Por meio da bios theôrétikos, pretendida por Platão, busca-se a contemplação permanente de um conhecimento perfeito e, nesse sentido, adjetivado por Arendt como divino. Para apresentar esse modelo de uma vida teorética, um dos primeiros movimentos da filosofia platônica, segundo Arendt, é criar uma dicotomia entre alma e corpo.

Essa dicotomia é fundamental, para Arendt, pois é ela quem suplanta e, em grande medida, quase apaga da história da filosofia a noção socrática de que no pensamento somos dois$e m-u m^{2}$. Por meio da divisão entre alma e corpo, Platão dá o passo final para a separação absoluta entre política e filosofia e fecha o contorno de sua Tirania da Verdade. Tal divisão pauta que tudo o que há de superior e de mais nobre se relaciona à alma. Já o corpo, que habita a pólis, se relaciona ao que é inferior. A alma se ocupa da filosofia, daquilo que é eterno, enquanto "as coisas dos homens" estão no âmbito do corpo. A alma governa o corpo, ela o domina e, nesse sentido, a dominação encontra-se justificada para Platão, pois o domínio aqui estabelecido é o do superior sobre inferior:

Quanto mais um filósofo se torna um verdadeiro filósofo, mais ele irá separar-se de seu corpo; e como, enquanto ele está vivo, tal separação nunca pode realmente acontecer, ele tentará fazer o que todo cidadão livre de Atenas fazia para separar-se e libertar-se das necessidades da vida: governará o seu corpo, como um senhor governa os seus escravos. Se o filósofo chegar ao governo da cidade, não fará aos seus habitantes nada além do que já fez a seu corpo. Sua tirania estará justificada tanto no sentido do melhor governo como no sentido da legitimidade pessoal, isto é, por sua obediência

\footnotetext{
${ }^{2} \mathrm{Na}$ segunda parte do texto, falaremos brevemente sobre a noção de dois-em-um.
} 
inicial, na condição de homem mortal, aos comandos de sua alma, na condição de filósofo. (ARENDT, 2002a, p. 107)

É, portanto, o homem que consegue priorizar a alma e a filosofia e, desse modo, contemplar a verdade, que deve guiar seus concidadãos. Para Arendt, é nesse sentido que Platão estabelece uma relação de senhor e escravo entre o filósofo e a cidade, resultando na separação entre filosofia e política. A polis deixa de ser o espaço da isonomia e das discussões entre os cidadãos presentes no modelo democrático para se estabelecer como a tirania de um em relação à maioria. Mas isso, segundo Arendt, é a posição de Platão, não a de Sócrates, e se configuraria, na verdade, como uma ruptura do discípulo com seu mestre. Cabe-nos, agora, compreender como a prática socrática relacionava a filosofia e a política, de acordo com a pensadora.

\section{A liberdade como o sentido da política}

Para Arendt, a filosofia socrática estava a serviço da pólis. Tratava-se, pois, de uma filosofia em busca de tornar os cidadãos "mais verdadeiros". Ao contrário de almejar que eles alcançassem as verdades eternas, o que Sócrates desejava era que os homens encontrassem a verdade em suas opiniões. Diferenciando-se de Platão, o filósofo pretendia, pois, aperfeiçoar as doxai daqueles que dele se aproximassem. Nesse sentido, Arendt considera que a maiêutica é uma atividade política: "um dar e receber baseado fundamentalmente na estrita igualdade, algo cujos frutos não podiam ser medidos pelo resultado obtido ao se chegar a esta ou àquela verdade geral" (ARENDT, 2002a, p. 97). É por isso que os primeiros diálogos de Platão são concluídos sem alcançar resultados: a discussão sobre a doxa de um cidadão já seria resultado suficiente para Sócrates.

Para melhor compreender esse ponto, Arendt propõe uma interessante interpretação: para ela, a máxima presente em Platão de que é inadmissível que o homem esteja em desacordo consigo mesmo e que é seguida por Aristóteles, também encontra algum eco em Sócrates: para que o homem diga sua doxa com verdade é essencial que ele esteja de acordo consigo mesmo (Cf. ARENDT, 2002a, p.100-101). Mas a contradição é algo presente na maioria de nós e ao mesmo tempo que a cometemos, tememos cometê-la. Afinal, ela é sempre uma possibilidade, 
pois quando pensamos somos, na verdade, dois-em-um: "já que eu sou um, não irei contradizerme, mas posso contradizer-me porque em pensamento sou dois-em-um; logo, não vivo apenas com os outros, enquanto um, mas também comigo mesmo" (ARENDT, 2002a, p. 101). 0 medo da contradição ${ }^{3}$ consiste no temor de deixar de ser um e é a descoberta socrática de que, em pensamento, somos dois-em-um que leva Aristóteles estabelecer o princípio da não-contradição. Essa é uma contribuição fundamental de Arendt para o pensamento político: embora a autora afirme que isso está em Sócrates, consideramos ser essa uma novidade da autora. A noção de que somos dois-em-um quando pensamos e que a pluralidade está dentro de cada um de nós é uma resposta da autora às imposições tirânicas e totalizadoras, tal como o que ela considera ser a “Tirania da Verdade" platônica. Do mesmo modo, ela inova ao defender que essa possibilidade de o homem estar em desacordo consigo mesmo seria o que leva Aristóteles a fundar sua lógica sobre o princípio de não-contradição ${ }^{4}$.

Além disso, Arendt também destaca que só é possível ao homem se relacionar com outra pessoa, como amigo, porque em seu pensamento ele dialoga consigo mesmo como se fosse um outro. Ora, a doxa apenas se aperfeiçoa por meio da discussão e ela só é possível, para mim, porque sou dois-em-um e porque dialogo a seu respeito com outras pessoas.

Esse tipo de diálogo se aproxima, sem dúvidas, à conversa entre amigos. A amizade consiste, em grande medida, em debater sobre o que há de comum entre as pessoas que conversam e nas palavras de Dana R. Villa, “essa 'política da conversa' evidencia a condição humana básica da pluralidade em que o discurso deliberativo entre iguais expressa perspectivas individuais sobre um mundo comum" (VILLA, 1999, p 156). Para falar sobre a amizade, Arendt recorre a Aristóteles e à compreensão de que a igualação política é a philia e que viver em conjunto na pólis é uma prerrogativa para a boa vida. A importância atribuída por Arendt à amizade reside na concepção de que existe nela um aspecto político:

\footnotetext{
${ }^{3}$ Arendt também discute o medo que nós, humanos, temos em "nos contradizer" e a criação da lógica como resposta a isso na obra Origens do totalitarismo (Cf. ARENDT, 1973, p. 473) Nas Origens, no entanto, esse medo da contradição possui consequências graves, pois em alguma medida isso abre espaço para a ideologia (no sentido arendtiano de "lógica de uma ideia") e, portanto, para adesão ao totalitarismo. Neste texto, no entanto, não abordamos esse aspecto do "medo da contradição", pois isso nos desviaria de nosso assunto.
} 
O elemento político, na amizade, reside no fato de que, no verdadeiro diálogo, cada um dos amigos pode compreender a verdade inerente à opinião do outro. Mais do que o seu amigo como pessoa, um amigo compreende como e em que articulação específica o mundo comum aparece para o outro que, como pessoa, será sempre desigual ou diferente. Esse tipo de compreensão - em que se vê o mundo (como se diz hoje um tanto trivialmente) do ponto de vista do outro - é o tipo de insight político por excelência. (ARENDT, 2002a, p. 99)

A filosofia, quando a serviço da política - a partir de uma possível compreensão socrática -, auxilia justamente no estabelecimento do mundo comum. Além disso, também é importante destacar que a doxa não é apenas “opinião", mas também "glória e fama” (Cf. ARENDT, 2002a, p. 106). Portanto, a doxa possui um aspecto duplamente político, pois em ambas denotações, a doxa se realiza no espaço público: as diferentes doxai se mostram a partir da discussão e do compartilhamento do mundo comum que se realizam entre iguais, esse é o primeiro sentido. Do mesmo modo, se compreendemos a doxa como "glória e fama" percebemos também uma relação direta com o político, pois é somente na esfera pública que o cidadão aparece e se mostra, ou seja, que ele é visto e ouvido pelos outros. Na democracia ateniense, é somente no espaço público que o cidadão poderá conquistar a glória.

Para os gregos, o espaço público possui uma incontestável superioridade em relação ao espaço privado. 0 espaço público é o lugar em que acontecem as discussões e no qual os homens se relacionam entre iguais - enquanto cidadãos que possuem o direito de estar na esfera pública. Além disso, conforme já dissemos, é somente nesse espaço que o destaque é possível, ou seja, em que se pode alcançar glória e fama. 0 espaço privado é o espaço desigual de dominação, no qual o homem domina a mulher e o seu escravo. Não há diálogo tal como os que se realizam na Ágora. 0 espaço privado, doméstico, é relegado às mulheres e escravos e, portanto, de importância ínfima.

A esse respeito também podemos destacar a concepção aristotélica de que o homem é um zoon lógon ékhon, "um ser que atinge sua possibilidade máxima na faculdade do discurso e na vida em uma pólis" (ARENDT, 1961, p. 23), concepção essa que fundamentava a distinção entre gregos e bárbaros e homens livres e escravos. Essa distinção se baseia, principalmente, no modo como os gregos conduziam seus negócios, por meio do discurso e da persuasão, e não pela violência ou coerção. Assim, fica evidente a supremacia do espaço público em relação ao 
privado: o espaço público é o espaço do discurso, da plena realização humana, o espaço privado é onde acontecem a violência e a coerção.

Ainda nos atendo à questão do aparecer e do espaço público, consideramos necessário nos remeter ao que Arendt concebe como o sentido da política. Novamente recorrendo à concepção grega de política, a autora defende que ela está diretamente atrelada à liberdade. De acordo com a escritora alemã, é a liberdade que diferencia a pólis de todas as outras formas de convívio entre os homens. Diferente da concepção de política como aquilo que possibilita e garante a liberdade, a tradição grega compreendia a liberdade e a política como indissociáveis uma da outra, "ser-livre e viver numa pólis eram, num certo sentido, a mesma e única coisa" (ARENDT, 2002b, p. 18) A autora destaca que essa indissociabilidade existe "num certo sentido" porque o homem precisa ser livre em outro sentido para poder viver em uma pólis.

Esse outro sentido é o ócio, a libertação de todo trabalho; com esse intuito, a escravidão era, para os gregos, o único meio para a dedicação plena à política. Ou seja, a liberdade política se ancorava, em certa medida, no domínio e na ausência da liberdade no âmbito privado e doméstico. Nas palavras de Arendt, "essa libertação realizava-se através da coação e da força e baseava-se no domínio absoluto que o dono da casa exercia em seu domicílio" (ARENDT, 2002b, p. 18). Sob esse aspecto, a política é entendida para os gregos como um "não ser dominado" e "não dominar" (ARENDT, 2002b, p. 18); sendo compreendida, também, como um espaço que só pode ser realizado a partir da reunião de muitos cidadãos livres que se relacionam na esfera pública como iguais.

Arendt pondera que tal concepção nos parece difícil de compreender, uma vez que consideramos, hoje, que é a igualdade, e não a liberdade, a fonte da justiça e, desse modo, frequentemente podemos interpretar erroneamente a noção de "isonomia". De acordo com Arendt, costumamos compreendê-la como "todos iguais perante a lei". No entanto, para os gregos, a isonomia não se refere a esse tipo de igualdade, mas sim, à igualdade de direito à política, sendo esta concebida pela autora como uma atividade de conversa mútua (ARENDT, 2002b, p. 19). A isonomia é, portanto, a liberdade de fala no espaço público e esse tipo de fala só é possível entre os cidadãos livres e, desse modo, "quando os gregos diziam que escravos e bárbaros eram aneu 
logou, não dominavam a palavra, queriam dizer que eles se encontravam numa situação na qual era impossível a conversa livre" (ARENDT, 2002b, p. 18).

A liberdade de fala, de acordo com Arendt, desde a antiguidade foi - e permanece ainda hoje -, de certo modo, ambígua. Essa liberdade não consiste em falar o que se deseja sobre qualquer assunto, mas sim compreender que nós só conseguimos ver o mundo em sua plenitude ao apreender as mais diversas visões e opiniões. É apenas ao falar sobre o mundo em comum, e ouvir o que outros têm a dizer sobre ele, que conseguiremos compreendê-lo. 0 mundo aparece para cada um de nós de maneira distinta e ao vê-lo sob outra perspectiva, pelo olhar do outro, nós alargamos a nossa compreensão a respeito dele:

Se alguém quiser ver e conhecer o mundo tal como ele é 'realmente', só poderá fazê-lo se entender o mundo como algo comum a muitos, que está entre eles, separando-os e unindo-os, que se mostra para cada um de maneira diferente e, por conseguinte, só se torna compreensível na medida em que muitos falarem sobre ele e trocarem suas opiniões, suas perspectivas uns com os outros e uns contra os outros. Só na liberdade do falar um com o outro nasce o mundo sobre o qual se fala, em sua objetividade visível de todos os lados. 0 viver-num-mundo-real e o falar-sobre-ele-com-outros são, no fundo, a mesma e única coisa, e a vida privada parecia 'idiota' para os gregos porque os privava dessa complexidade do conversar-sobre-alguma-coisa e, com isso, da experiência sobre como a coisa acontecia, de fato, no mundo (ARENDT, 2002b, p. 23).

É essa, portanto, a liberdade de fala política: a possibilidade de entender o mundo sob formas variadas e de debater sobre esse mundo em comum. Liberdade, esta, que era nula no espaço privado, onde a coerção e a dominação suplantavam a conversa. Ora, nosso ponto aqui é destacar que, para Arendt, a política é necessariamente pensada de modo imbricado à liberdade, que se identifica e equivale ao próprio sentido da política. Para a filósofa, a violência e a pressão só devem ser compreendidas como "meios para proteger o espaço político, ou para fundá-lo e ampliá-lo", mas eles não são processos propriamente políticos. Eles são, na verdade, "fenômenos marginais que pertencem ao fenômeno da coisa política" (ARENDT, 2002b, p. 23) e não devem, portanto, ser confundidos com a política em si mesma.

Ora, se hoje percebemo-nos como incapazes de realizar a política em tais termos, isso ocorre por uma degradação que teve seu início com Platão. De acordo com Arendt, a proposta do rei filósofo, feita pelo discípulo de Sócrates, consistia na dominação e submissão da maioria, de modo que poucos usufruíssem da liberdade de filosofar. Ainda que essa proposta nunca 
tenha sido retomada ou reformulada por nenhum outro filósofo, a fundação da Academia representa um espaço para a liberdade de poucos, que se estabelece em "completa contradição com a liberdade política da praça do mercado", isso porque, para Platão, o mundo da verdade, "e do falar adequado à verdade; a arte retórica, a ciência da dialética" deveria se opor ao "mundo das opiniões mentirosas e do falar enganador" (ARENDT, 2002b, p. 25). Para Arendt, o que se estabelece com Platão não resulta em uma tentativa de a Academia determinar a pólis, mas sim em um afastamento da filosofia em relação à política.

0 decisivo nesse contexto não é tanto o conflito entre a polis e os filósofos, mas sim não poder persistir a simples indiferença de um âmbito em relação ao outro, na qual o conflito pareceu solucionado por um momento, porquanto impossível o espaço da minoria e sua liberdade (...). É evidente que a minoria, sempre que se separou da maioria - seja na forma de uma indiferença acadêmica, seja na forma de um domínio oligárquico - , caiu numa dependência da maioria, em todas as questões da vida em comum nas quais realmente se tinha de negociar. Assim, essa dependência no sentido de uma oligarquia platônica pode ser entendida como obrigação da maioria em cumprir as ordens da minoria, quer dizer, assumir o verdadeiro agir; nesse caso, a dependência da minoria foi superada pelo domínio, assim como a dependência dos livres em relação às necessidades da vida pôde ser superada por meio de seu domínio sobre uma casa de escravos, e a liberdade basear-se no poder (ARENDT, 2002b, p. 25).

Essa noção perdura até hoje em nossa concepção sobre política e liberdade. A liberdade, hoje, não possui mais o sentido político que Arendt defende ser o norteador da pólis. Nos dias atuais, é amplamente difundida a compreensão da política como aquilo que preserva a vida e as liberdades meramente individuais. A liberdade deixa de ser o sentido da política e passa a ser concebida como algo que a política deve garantir. A noção de liberdade política é suplantada pela noção de que liberdade de viver e existir devem ser garantidas pela política. Nesse sentido, a própria Academia - ou a universidade - só pode existir dentro da pólis, ou seja, a pólis passa a ser aquilo que garante a liberdade de a Academia existir. Para Arendt, essa concepção de política como asseguradora de bens fundamentais para a reprodução e manutenção da vida é uma degradação da política. A autora ainda nos chama a atenção para o fato de que, a partir dessa noção, liberdade e política continuam a se relacionar, mas não possuem mais uma relação de identidade.

Ora, essa degradação da política destacada por Arendt resulta, por fim, em uma perda de sentido da política, à medida que ela deixa de ser uma atividade que não necessita de 
justificações externas para se tornar um meio de garantia para as liberdades individuais ou para a reprodução da vida. Na modernidade, a concepção de que o Estado é "uma função da sociedade ou um mal necessário para a liberdade social" (ARENDT, 2002b, p. 25) alcança força, consolidando-se como uma concepção corrente. Ganha notoriedade, também, a partir do advento do capitalismo, a ideia de que o Estado "libertaria" os homens para a execução das atividades de produção de mercadoria e de consumo. A "vida feliz" já não alcança sua realização na pólis, mas nos produtos que o capitalismo gera.

Outro ponto importante, analisado pela autora, é a respeito da "força" utilizada pelos meios públicos. Isso porque esses meios, que deveriam proteger a liberdade, possuem, no Estado moderno, a possibilidade de levar a espécie humana a seu fim. A partir da criação da bomba atômica, o extermínio da humanidade passa a ser um perigo real e, portanto, surgem novas preocupações e questionamentos para o campo da política:

Em todo caso, a pergunta sobre o sentido da política diz respeito hoje à conveniência ou inconveniência desses meios públicos de força; ela surge do simples fato de a força que devia proteger a vida ou a liberdade tornar-se tão terrivelmente poderosa que ameaça não apenas a liberdade, mas sim a vida. Como é justamente o aumento dos meios estatais de força que põe em perigo o processo de vida de toda a Humanidade, a resposta - em si já bastante duvidosa - que os tempos modernos oferecem à pergunta sobre o sentido da política tornou-se hoje duplamente duvidosa (ARENDT, 2002b, p. 30).

No entanto, devemos destacar que não são apenas os recursos tecnológicos que colocam essa ameaça em voga, mas sim o próprio modo como a força é compreendida e incorporada pela política: o espaço público deixou de ser a esfera da conversa e passou a ser "um lugar de força”. É importante notar ainda que ao mesmo tempo em que se eliminou, na concepção de Arendt, a dominação do homem em relação a outro homem - com o fim da escravidão e a emancipação econômica das mulheres - a força pública, do Estado, aumentou, "para poder existir sem força na vida cotidiana, o homem fortaleceu a força da mão pública, do Estado" (ARENDT, 2002b, p. 32).

O problema do uso da força pelas mãos do Estado consiste não apenas no claro rebaixamento da política, mas também no fato de que aquele que deveria garantir a vida das pessoas passa a ser uma ameaça. Para Arendt, a gravidade do uso da força aumenta quando ela se alia 
ao poder, o que só pode acontecer à medida que o Estado detém a força. Ora, ainda que a força exercida em âmbito privado seja extremamente prejudicial para aqueles que sofrem com a dominação, ela não é comparável à que reside em âmbito público. A força doméstica "estava sempre limitada ao indivíduo que a exercia; era uma força totalmente impotente que continuava estéril tanto econômica como politicamente" (ARENDT, 2002b, p. 32), enquanto a força política representa um perigo absurdamente maior ao passo que o extermínio da humanidade passa a ser um mecanismo real. Quando o Estado se revela como ameaça, com o poder de extinguir aquilo que ele deveria manter e proteger, ou seja, a própria vida das pessoas, instaura-se uma crise na política. Tal crise evidencia-se, segundo Arendt, quando a pergunta "qual é o sentido da política?" é suplantada pelo questionamento: "tem a política ainda algum sentido?" (ARENDT, 2002b, p. 32).

Tendo em vista esse cenário em que a própria existência da política passa a ser questionada, resta-nos, como desafio e tarefa, pensar de que modo o verdadeiro sentido da política pode ser reestabelecido em nossos dias. Se a cisão entre filosofia e política se dá, principalmente, a partir do conflito do filósofo com o espaço público, cabe-nos refletir se é possível sua introdução nessa esfera, não mais para propor uma tirania do filósofo, mas para defender uma política que esteja alinhada à prática do diálogo e do pensamento.

\section{Conclusão}

Segundo a concepção de Arendt, a filosofia de Platão não apenas resultou na cisão entre filosofia e política, como também degradou a própria noção de política grega ao defender uma sociedade baseada na dominação e não na liberdade. A partir da condenação de Sócrates e, posteriormente, de uma tentativa da cidade de fazer o mesmo com Aristóteles, os filósofos passaram a desejar que a pólis apenas os "deixassem em paz", ou seja, livres para filosofar e sem nenhuma necessidade de atuação no espaço público.

Por outro lado, a filosofia socrática até então havia sido, de acordo com Arendt, uma filosofia a serviço da pólis. A importância conferida ao diálogo e o aprimoramento da doxa estavam em perfeita consonância com a valorização grega do espaço público. A cisão ocorre a 
partir da condenação injusta sofrida por Sócrates: Arendt interpreta que Platão viu nesse acontecimento a decadência da pólis e da democracia e, portanto, ao ver esse grande filósofo ser condenado injustamente pela cidade, seu mais notável discípulo passou a enxergá-la com enorme descrédito. Para Arendt, quando Platão propõe o que a autora considera como "a tirania da verdade" ele se opõe ao verdadeiro sentido da política, que é a liberdade e a pluralidade.

Em seu texto $O$ sentido da política estudado aqui, Arendt nos mostra uma crescente perda de sentido da política, à medida que ela deixa de se identificar com a liberdade. Essa modificação em seu sentido resulta na degradação da política, que passa a ser ela própria questionada. Isso é facilmente percebido mesmo hoje, em 2021, quando notamos a ascensão de pessoas que se apresentam como "outsiders" aos mais altos postos de poder a partir do discurso “antipolítica”, apostando, portanto, no completo rebaixamento da política. Diante dessa situação, cabe-nos indagar e refletir, para além de Arendt, se é possível que a filosofia política se reestabeleça e, ainda, qual é o papel do filósofo diante desse cenário de crise.

\section{Bibliografia}

ARENDT, Hannah. A dignidade da política. Rio de Janeiro: Relume Dumará, 2002a.

_. Between Past and Future: Six exercises in political thought. Nova York: The Viking Press, 1961.

_... que é política? Rio de Janeiro: Bertrand Brasil, 2002b.

Versão eletrônica. Disponível em: http://arquivos.eadadm.ufsc.br/somente-leitura/EaDADM/UAB_2017_1/Modulo_1/Ciencia\%20Politica/Material\%20Complementar/0\%20que\%20\%C3\%A9\%20pol\%C3\%ADtica\%20Hannah\%20Arendt.pdf. Acesso em: 22 de junho de 2021.

_. The origins of totalitarianism. Orlando: Harcourt Brace \& Company, 1973.

MORAES, Eduardo Jardim de. Hanna Arendt: Filosofia e Política. In: MORAES, Eduardo Jardim de.; BIGNOTTO, Newton. (Org.). Hannah Arendt: Diálogos, reflexões, memórias. Belo Horizonte: Editora UFMG, 2003.

SILVA, Adriano Correia. Hannah Arendt e a Modernidade: Política, Economia e a Disputa por uma Fronteira. Rio de Janeiro: Forense Universitária, 2014.

VILLA, Dana R. Politics, Philosophy, Terror. Nova Jersey: Princeton Press, 1999.

The Cambridge Companion to Hannah Arendt. Cambridge: Cambridge University Press, 2001. 
PERSPECTIVAS | VOL. 6, № 2, 2021, P. 319-334

0 distanciamento entre filosofia e política, e o sentido da política em Hannah Arendt DOI: $10.20873 / \mathrm{rpv} 6 \mathrm{n} 2-17$

\section{Tamíris Moreira Simão}

Doutoranda em Filosofia na UFMG. 